\title{
Chapter 22 \\ Mammalian Two-Hybrid Assay for Detecting Protein-Protein Interactions in Vivo
}

\author{
Runtao He and Xuguang Li
}

\begin{abstract}
The mammalian two-hybrid system is a very powerful tool to investigate protein-protein interactions in terms of functional domains and identify potential binding ligands and partners of a protein. Compared with the yeast two-hybrid system, the mammalian two-hybrid system provides the milieu for the bona fide posttranslational modifications and localizations of most eukaryotic proteins and, therefore, should be a better choice to study proteins of mammalian origin. This chapter depicts the detailed experimental procedures adapted by various laboratories. Researchers with experience in molecular biology could modify the procedures according to their own needs, that is, the choice of restriction sites in the cloning process. The reference list could be of use to researchers who wish to understand more of the system and explore its wider applications.
\end{abstract}

Keywords mammalian two hybrid, secreted alkaline phosphatase (SEAP), protein-protein interaction, PCR, cloning

\section{Introduction}

Protein-protein interaction is one of the most important mechanisms utilized by mammalian cells to regulate a variety of cellular and molecular activities, such as transcription, translation, signal transduction and enzyme reaction $[1,2]$. Proteins of microorganisms also interfere with host cell proliferation and functions by interacting with intracellular proteins [3]. There are various methods to characterize protein-protein interactions including coimmunoprecipitation, mass spectrometry [4], chemical cross-linking [5], and the two-hybrid system [6, 7], which has been used widely in recent years because of its high-throughput screening capability and powerful ability of isolating unknown binding partners of a protein. The first two-hybrid system was yeast based and was introduced by Fields and Song in 1989 [8]. It is composed of two GAL-based transcription activation domains of Saccharomyces cerevisiae, one is the DNA binding 
domain (DBD) domain, while the other is the transcription activation domain (AD). To perform the two-hybrid analysis, an $\mathrm{X}$ gene is cloned into a two-hybrid vector fusing to $\mathrm{DBD}$, with a $\mathrm{Y}$ gene cloned into another two-hybrid vector fused to the $\mathrm{AD}$. If the $\mathrm{X}$ protein interacts with $\mathrm{Y}$ protein, the $\mathrm{DBD}$ and $\mathrm{AD}$ domains come into close proximity and form an active transcription activation complex (Fig. 22.1). The complex binds to and activates its cognate promoter sequence, which is linked to a reporter gene(s), such as Lac Z, or an essential nutrient [8]. These gene products generate distinctive phenotypes that can be easily recognized by a change of color of yeast colonies or a gained ability to grow in nutrient-deficient media.

A lot of modifications have been made to improve the sensitivity and specificity of the two-hybrid system: the addition of more reporter genes and genetic alterations of the DBD and AD domains, such as the LexA system $[9,10]$. However, the yeast-based two-hybrid assay has its limitations. One major issue is that posttranslational modifications such as glycosylation in yeast can be quite different from that in mammalian cells. In addition, the intracellular milieu that supports the protein-protein interaction in yeast is different from that of mammalian cells $[11,12]$. Therefore, when considering the study of interactions of proteins derived from mammalian cells, the yeast system may not be able to provide the optimal intracellular environment.

\section{$\mathrm{Y} \quad \mathrm{AD}$}

\section{DBD $\mathrm{X}$}

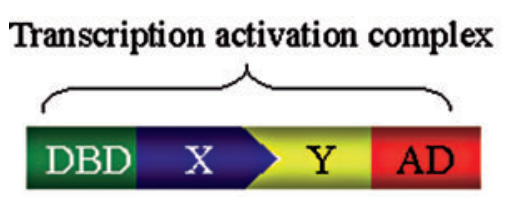

Promoter

\section{Transcription}

Reporter gene

Fig. 22.1 Principles of the-two hybrid system: DBD and AD are DNA binding and transcriptional activation domains, $\mathrm{X}$ and $\mathrm{Y}$ are the bait and prey genes 
To alleviate the pitfalls of the yeast two-hybrid system, the mammalian twohybrid system was introduced.

The design of the mammalian two-hybrid system is similar to that of the yeast two-hybrid system, which is composed of two vectors carrying DNA binding domain and DNA activation domain, respectively, in two mammalian expression vectors. Two genes of interest ( $\mathrm{X}$ and $\mathrm{Y}$ ) are cloned into the vectors and fused with DBD and DA, correspondingly. The interaction of protein $\mathrm{X}$ to protein $\mathrm{Y}$ brings the $\mathrm{DBD}$ and $\mathrm{AD}$ to a close proximity and forms the transcriptional activation complex, which binds to the promoter of a reporter gene encoded in a reporter plasmid and starts the gene transcription. The reporter genes can be secreted alkaline phosphatase (SEAP), chloramphenicol acetyl transferaseor (CAT), or luciferase [13-15]. GAL4 DNA binding domain and herpes virus DNA transcription activator VP16 are commonly used in mammalian two-hybrid systems [16]. This chapter depicts the general procedure adopted by various laboratories.

\section{Materials}

\subsection{PCR and Cloning of Genes of Interest into Mammalian Two-Hybrid Vectors}

1. High fidelity DNA polymerase (i.e., iProof high fidelity DNA polymerase, BioRad).

2. dNTPs at $25 \mathrm{~m} M$ concentration (New England Biolabs).

3. PCR primers (cloning sites are added to the $5^{\prime}$ ends of the primers):

5' GTACGAATTCATGTCTGATAATGGACCC 3'. 5' GTACGGATCCTTATGCCTGAGTTGAATCAG 3'.

4. PCR template (cDNA reversely transcribed from SARS-CoV genome).

5. Thermal cycler, such as Master Cycler EP (Eppenforf).

6. Thin-wall PCR tubes or 96-well plates.

7. Ampicillin (Sigma-Aldrich).

8. PCR Kleen Spin Columns (BioRad).

9. Restriction enzymes: Eco RI and Bam HI (New England Biolabs).

10. Mammalian two-hybrid system with $\mathrm{pM}$ and $\mathrm{pVP16}$ vectors (Clontech).

11. T4 DNA ligase (New England Biolabs).

12. Taq polymerase for colony screening assay (i.e., HotStar PCR Master Mix Kit, Qiagen).

13. Water bath at $37^{\circ} \mathrm{C}$.

14. Chemical or electro competent cells (Invitrogen).

15. Water bath at $42{ }^{\circ} \mathrm{C}$.

16. Qiaprep Spin Miniprep Kit (Qiagen). 
17. 10X TBE buffer: $108 \mathrm{~g}$ of Tris-base, $55 \mathrm{~g}$ of boric acid, $9.3 \mathrm{~g}$ of Na-EDTA, and add $\mathrm{ddH}_{2} \mathrm{O}$ to $1 \mathrm{~L}$.

18. Agarose (Invitrogen).

19. LB (Luria Broth) per liter: bacto-tryptone $10 \mathrm{~g}$, bacto-yeast extract $5 \mathrm{~g}, \mathrm{NaCl}$ $10 \mathrm{~g}, \mathrm{pH} 7.0 ; \mathrm{ddH}_{2} \mathrm{O}$ to make $1 \mathrm{~L}$.

20. Preparation of LB agarose plates: add $15 \mathrm{~g}$ of agarose to $1 \mathrm{~L}$ of $\mathrm{LB}$ media and autoclave for $20 \mathrm{~min}$, cool to $45^{\circ} \mathrm{C}$, and dispense approximately $25 \mathrm{~mL}$ into per 100 -mm plate.

21. SOC medium per liter: add $2 \%$ bacto-tryptone, $0.5 \%$ yeast extract, $10 \mathrm{~m} M$ $\mathrm{NaCl}, 2.5 \mathrm{~m} M \mathrm{KCl}, 10 \mathrm{~m} M \mathrm{MgCl}_{2}, 10 \mathrm{~m} M \mathrm{MgSO}_{4}, 20 \mathrm{~m} M$ glucose, $\mathrm{pH} 7.0$, and bring the final volume to $1 \mathrm{~L}$ with $\mathrm{ddH}_{2} \mathrm{O}$.

22. Shaking incubator (Thermo Electron Corporation).

23. $20 \%$ glycerol solution (v/v).

\subsection{DNA Purification for Mammalian Cell Transfection}

1. Endofree Plasmid Maxi Kit (QIAGEN).

2. 70\% ethanol v/v (for the QIAGEN Maxi Plasmid Kit).

3. $99 \%$ isopropanol (for the QIAGEN Maxi Pladmid Kit).

4. 50-mL tissue culture conical tubes.

5. Ultracentrifuge tubes.

6. TE buffer: $10 \mathrm{~m} M$ Tris-HCl; $1 \mathrm{~m} M$ EDTA, $\mathrm{pH}$ 8.0.

\subsection{Tissue Culture}

1. Growth medium: Dulbecco's Modified Eagle Medium (Invitrogen).

2. Fetal calf serum (Invitrogen).

3. 100X penicillin/streptomycin (Invitrogen).

4. Vero E6 cells (ATCC).

5. $0.5 \%$ trypsin-EDTA (Invitrogen).

6. Phosphate buffered saline: $8 \mathrm{~g} \mathrm{NaCl}, 0.2 \mathrm{~g} \mathrm{KCl}, 1.44 \mathrm{~g} \mathrm{Na}_{2} \mathrm{HPO}_{4}, 0.24 \mathrm{~g} \mathrm{KH}_{2} \mathrm{PO}_{4}$, add double distilled $\mathrm{H}_{2} \mathrm{O}$ to $1 \mathrm{~L}$. $\mathrm{pH} 7.4$.

7. 24-well tissue culture plates (Nalgene Nunc).

8. Water bath set at $37^{\circ} \mathrm{C}$.

9. Inverted microscope (Zeiss).

10. Hemacytometer (VWR).

11. Tissue culture incubator (Thermo Electron Corporation).

\subsection{Transfection and Mammalian Two-Hybrid Analysis}

1. Transfection reagent: Effectene (QIAGEN).

2. pM and pVP-based constructs (Clontech, Palo Alto, CA). 
3. pG5SEAP reporter vector (included in the mammalian two-hybrid kit).

4. SEAP (secreted alkaline phosphatase) Chemiluminescent Assay Kit (Clontech).

5. 96-well chemiluminescence reader (Tecan) or single-well chemiluminescence reader (Turner Designs).

6. 96-well PCR plates.

\section{Methods}

\subsection{PCR Amplification of Genes of Interest and Preparation of Mammalian Two-Hybrid Vectors}

\subsubsection{PCR Reaction}

1. Add $10 \mu \mathrm{L}$ of iProof HF buffer, $1 \mu \mathrm{L}$ of dNTP, two primers at $500 \mathrm{n} M$ each, $0.5 \mathrm{U}$ of DNA polymerase, a PCR template for the genes of interest, and $\mathrm{ddH}_{2} \mathrm{O}$ to $50 \mu \mathrm{L}$.

2. PCR conditions: after $30 \mathrm{~s}$ of the initial denaturation at $98^{\circ} \mathrm{C}$, run $25-35$ cycles of the following steps-denaturation at $98^{\circ} \mathrm{C}$ for $10 \mathrm{~s}$, annealing at $45-72^{\circ} \mathrm{C}$ for $30 \mathrm{~s}$, and extension at $72{ }^{\circ} \mathrm{C}(15-20 \mathrm{~s}$ per kb).

3. Clean PCR products with PCR Kleen columns, according to the manufacturer's protocol and elute DNA into a TE buffer.

4. Subject the PCR product to $1.2 \%$ agarose gel for electrophoresis, then isolate the band corresponding to the size of the desired gene. Purify the DNA from the gel piece using the Qiagen DNA Gel Purification Kit (optional step).

\subsubsection{Vector Preparation}

1. Inoculate two single colonies of $E$. coli top 10 strain containing pM and pVP16 vectors into $5 \mathrm{~mL}$ of $\mathrm{LB}$ respectively, add ampicillin to $100 \mu \mathrm{g} / \mathrm{mL}$ and grow in a shaking incubator at $37^{\circ} \mathrm{C}$ and shake at $250 \mathrm{rpm}$ overnight.

2. Harvest the cells by centrifugation at $10,000 \mathrm{~g}$ for $1 \mathrm{~min}$.

3. Isolate the constructs using the Qiaprep Spin Miniprep Kit (Qiagen).

\subsection{Cloning PCR Genes of Interest into of pM, pVP16 Vectors}

\subsubsection{Restriction Digestion}

In designing the primers, EcoRI and BamH I sites were added to the $5^{\prime}$ ends of the two PCR primers not present in the genes to be cloned. Cloning at EcoRI site fuses the gene of interest in frame with both DBD and AD domains. 
1. Digest pM and pVP vectors (150ng each) with $3 \mathrm{U}$ of EcoRI and BamHI, respectively, in $2 \mu \mathrm{L}$ EcoRI buffer supplied by the manufacturer in $20 \mu \mathrm{L}$ reaction mixture. Incubate at $37^{\circ} \mathrm{C}$ for $1 \mathrm{~h}$.

2. Digest PCR products flanked with EcoRI and BamHI sites on the $5^{\prime}$ and $3^{\prime}$ ends respectively, using conditions just described.

3. Clean the digested vectors and PCR products with PCR Kleen columns.

\subsubsection{Ligation}

1. Add $100 \mathrm{ng}$ of digested $\mathrm{pM}$ or $\mathrm{pVP} 16$ vector, $500 \mathrm{ng}$ of digested PCR product, $2 \mu \mathrm{L}$ of T4 Ligase buffer, $1 \mathrm{U}$ of T4 ligase, and add $\mathrm{ddH}_{2} \mathrm{O}$ to $20 \mu \mathrm{L}$.

2. Incubate at $16^{\circ} \mathrm{C}$ for overnight.

\subsubsection{Transformation}

1. Thaw and aliquot $50 \mathrm{~mL}$ top 10 chemical competent cells into an Eppendorf tube $\left(1 \times 10^{8}\right.$ cells $\left./ \mathrm{mL}\right)$, and chill on ice for $30 \mathrm{~min}$.

2. Add $10-50 \mathrm{ng}$ of the previously ligated products (see Sect. 3.2.2) into the previous $E$ coli cells.

3. Immediately transfer the Eppendorf tube to a $42^{\circ} \mathrm{C}$ water bath and incubate for $45 \mathrm{~s}$.

4. Add $1 \mathrm{~mL}$ of SOC buffer and incubate in a shaking incubator at $37^{\circ} \mathrm{C}$ for $30 \mathrm{~min}$. Transfer the transformed $E$ coli cells to a LB-ampicillin plate and incubate at $37^{\circ} \mathrm{C}$ for $1 \mathrm{~h}$. Turn the plate upside down and incubate at the same condition overnight.

\subsubsection{Screening for Clones That Contain the Gene of Interest}

There are many ways to screen for colonies that contain the gene of interest. In this protocol, we introduce a PCR-based screening, which is fast, simple, specific, and economical.

1. Perform PCR reaction with Taq polymerase. For each screening, prepare a master PCR-mix sufficient for 5-10 PCR reactions ( $48 \mu \mathrm{L} /$ per PCR). The master mix is prepared by adding appropriate PCR buffer, dNTPs, polymerase, primers used for the previous PCR amplifications of the genes of interest or other primers that can amplify the gene, and $\mathrm{ddH}_{2} \mathrm{O}$.

2. Aliquot this PCR mix into 5--10 PCR tubes.

3. Pick a single colony and dip into the PCR mix, then dip the residual of the colony onto a LB-ampicillin master plate with numbers labeled on the bottom. The master plate is incubated at $37^{\circ} \mathrm{C}$ overnight. 
4. Perform PCR cycling using following program: 1 cycle of $95^{\circ} \mathrm{C}$ for $10 \mathrm{~min}$; $40-45$ cycles of $95^{\circ} \mathrm{C}$ for $1 \mathrm{~min}, 45-72^{\circ} \mathrm{C}$ for $30 \mathrm{~s}$, and $72{ }^{\circ} \mathrm{C}$ at $1 \mathrm{~kb} / \mathrm{min}$.

5. Subject PCR products to electrophoresis with 1.2\% TBE agarose gel prepared in $1 \mathrm{X}$ TBE buffer. Samples with a band corresponding to the desired size are the potential positive clones.

6. Inoculate the positive colonies from the master LB-ampicillin plate into $5 \mathrm{~mL}$ of culture, incubate at $37^{\circ} \mathrm{C}$ overnight, then perform DNA Maxiprep as described next (see Sect. 3.3).

7. Sequence the selected plasmids to verify the correct DNA sequence.

8. The positive $E$ coli clone should be stored in LB-ampicillin broth containing $20 \%$ glycerol at $-80^{\circ} \mathrm{C}$.

\subsection{Large-Scale, High-Purity DNA Purification}

1. Inoculate from the master plates just described containing pM and pVP16 constructs selected from the previous screenings into two culture tubes with $5 \mathrm{~mL}$ LB-ampicillin and incubate overnight at $37^{\circ} \mathrm{C}$.

2. Transfer these two $5 \mathrm{ml}$ culture into two culture flasks containing $100 \mathrm{~mL}$ of LB plus ampicillin $(100 \mu \mathrm{g} / \mathrm{mL})$ and incubate until $\mathrm{A}_{600}=1.0-1.1$ (approximately $1 \times$ $10^{9} \mathrm{cell} / \mathrm{mL}$ ).

3. Harvest the cells by centrifugation at $4{ }^{\circ} \mathrm{C}$ for $10 \mathrm{~min}$. at $5,000 \mathrm{~g}$.

4. Isolate the $\mathrm{pM}$ and pVP16-based constructs using a Qiagen Endofree Plasmid Maxi Kit, following the manufacturer's protocol.

\subsection{Tissue Culture and Transfection}

\subsubsection{Culturing and Preparing Vero E6 Cells}

1. Supplement DMEM medium with $10 \%$ heat-inactivated fetal bovine serum and $1 \%$ penicillin/streptomycin.

2. Maintain the Vero E6 cells (African green monkey kidney cells) in culture flasks inside a humidified incubator at $37^{\circ} \mathrm{C}$ supplied with $5 \% \mathrm{CO}_{2}$.

3. To set up cell culture plates: Wash the cells with PBS, then treat the cells with $0.5 \%$ trypsin-EDTA before incubation at $37^{\circ} \mathrm{C}$ for $5-10 \mathrm{~min}$. Add $5 \mathrm{~mL}$ of the supplemented DMEM to the culture flask, transfer the supernatant into a screwtop conical tube, and spin at 1,500 $\mathrm{g}$ for $5 \mathrm{~min}$. Aspirate out the supernatant and add fresh medium to make the final concentration at 150,000 cells $/ \mathrm{mL}$.

4. Aliquot $0.5 \mathrm{~mL}$ of these cells into each well of a 24 -well plate $(75,000$ cells/ well), then incubate at $37^{\circ} \mathrm{C}$ overnight in a humidified chamber supplemented with $5 \% \mathrm{CO}_{2}$. 


\subsubsection{Transfection}

1. Sample arrangement: the following six samples are recommended for each mammalian two-hybrid analysis (see Table 22.1). All samples should be three to four repeat sets.

2. For each transfection: add $150 \mu \mathrm{L}$ EB buffer, $8 \mu \mathrm{L}$ enhancer, $1 \mu \mathrm{g}$ DNA (400ng pM-X, 400ng pVP16-Y, and 200ng pG5SEAP), followed by incubation for $5 \mathrm{~min}$ at room temperature. Afterward, add $15 \mu \mathrm{L}$ effectene (Qiagen) and incubate at room temperature for $10 \mathrm{~min}$.

3. Add $40 \mu \mathrm{L}$ of this transfection mix dropwise into each well of a 24 -well plate, three or four repeats of each sample is needed to generate standard deviation when SEAP assay is performed later.

4. Gently shake the culture plate to mix, then incubate in a tissue culture chamber supplemented with $5 \% \mathrm{CO}_{2}$ at $37^{\circ} \mathrm{C}$ for $48 \mathrm{~h}$.

\subsection{SEAP Analysis (Chemiluminescence)}

\subsubsection{SEAP Reaction}

1. Aliquot $100 \mu \mathrm{L}$ of the precedinjg cell culture supernatants from each well, transfer to an Eppdorf tube, and spin for $1 \mathrm{~min}$ at $10,000 \mathrm{~g}$.

2. Add $15 \mu \mathrm{L}$ of $1 \mathrm{X}$ dilution buffer from the GreatEscape SEAP Chemiluminescence Kit into each well of a conical bottom 96-well plate.

3. Add $40 \mu \mathrm{L}$ of the cell culture supernatant into each well of the 96 -well plate.

4. Seal the wells with adhesive aluminum foil pads, and incubate at $65^{\circ} \mathrm{C}$ for $30 \mathrm{~min}$.

5. Cool the plate on ice for $3 \mathrm{~min}$ and equilibrate the plate to room temperature.

6. Add $60 \mu \mathrm{L}$ of assay buffer to each well and incubate for $5 \mathrm{~min}$ at room temperature.

7. Mix 1:20 ratio of chemiluminescent enhancer and CSPD SEAP substrate.

8. Add $60 \mathrm{~mL}$ of the mix to each well and incubate the reaction mixture for $15-30 \mathrm{~min}$ at room temperature.

Table 22.1 Sample arrangement of mammalian two-hybrid assays

\begin{tabular}{llll}
\hline Sample number & $\mathrm{pM}$ & $\mathrm{pVP16}$ & pG5SEAP vector \\
\hline 1 & $\mathrm{pM}-\mathrm{X}$ & $\mathrm{pVP16-Y}$ & pG5SEAP vector \\
2 & $\mathrm{pM}$ & PVP16 & pG5SEAP vector \\
3 & $\mathrm{pM}$ & pVP16-Y & pG5SEAP vector \\
4 & pM-X & PVP16 & pG5SEAP vector \\
5 & pM-p53 & pVP-(SV40)T & pG5SEAP vector \\
6 & Blank & Blank & Blank \\
7 & Blank & Blank & pG5SEAP vector \\
\hline
\end{tabular}

Note: In the array of transfection for mammalian two-hybrid analysis, the pM, pVP, and pG5SEAP plasmid constructs are added in 2:2:1 ratio. Each combination should be transfected in triplicates or quadruplicates to obtain the optimal level of standard deviation for SEAP analysis. 


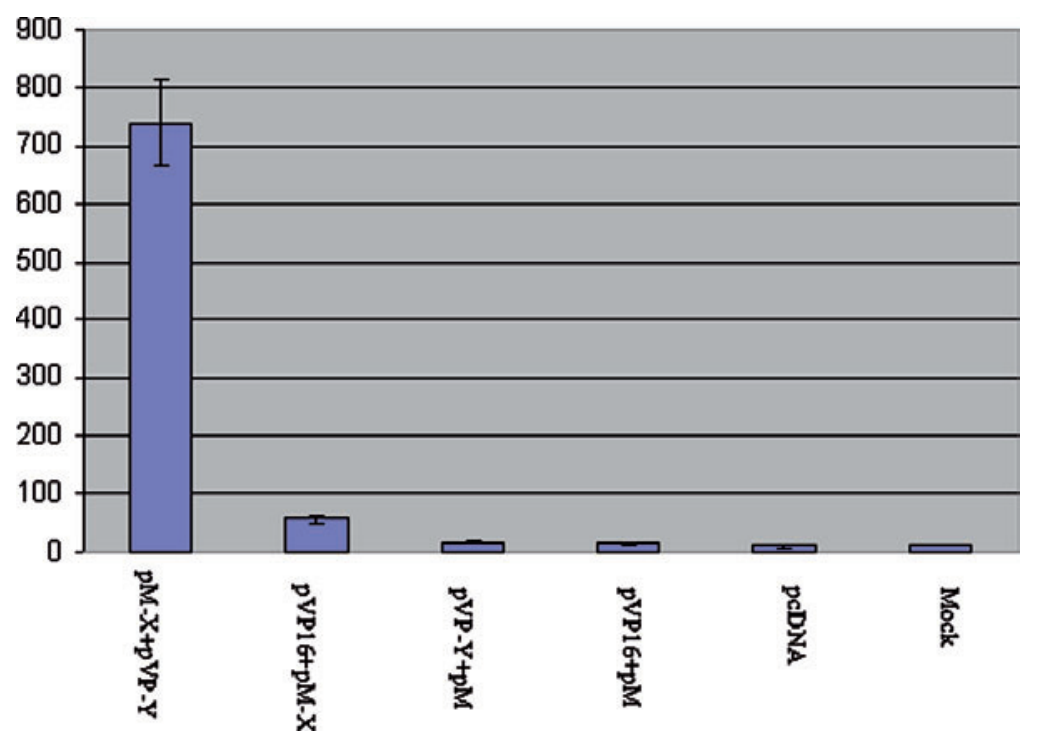

Fig 22.2 SEAP analysis: Chemiluminescence readings of the transfected samples. The depicted constructs were transfected in triplicate, $48 \mathrm{~h}$ after transfection, supernatant samples were harvested and subjected to SEAP analysis. The levels of chemiluminescence readings reflect the kinetics of protein-protein interactions

\subsubsection{Detection of Chemiluminescence Using Luminometers}

1. Detect chemiluminescence using a suitable detector (96-well or a single-tube luminometer can be used for this purpose.

2. Record the readings for phenotype analysis (see Fig. 22.2).

\section{Notes}

1. The quality of DNA for transfection is very important, we recommend $\mathrm{OD}_{260 / 280}$ to be at least 1.5. The large scale DNA preparation should be aliquoted into several Eppendorf tubes and frozen at $-20^{\circ} \mathrm{C}$ because frequent freeze-thaw cycles with the same tube may decrease the quality of DNA and affect the analysis.

2. Sometimes the Gal or the VP16 fusion peptides in $\mathrm{pM}$ or $\mathrm{pVP} 16$ vectors affects the conformation of the targeted protein, it is recommended that $\mathrm{pM}-\mathrm{X}+$ pVP16-Y, $\mathrm{pM}-\mathrm{Y}$, and $\mathrm{pVP} 16-\mathrm{X}$ are analyzed to avoid false negative results.

3. Cells should be $50-70 \%$ confluent to allow optimal transcription and translation of the targeted gene.

4. The combination of $\mathrm{pM}-\mathrm{X}+\mathrm{pVP}-\mathrm{X}$ is recommended for analysis because many functional forms of proteins are dimers or multimers. In this case, $\mathrm{X}=\mathrm{Y}$. The constructs used in this chapter are SARS-CoV nucleocapsid protein in $\mathrm{pM}$ and $\mathrm{pVP} 16$ vectors $(\mathrm{X}=\mathrm{Y})$. 
5. The transcription of $\mathrm{pM}$ and $\mathrm{pVP} 16$ vectors are controlled by a SV40 promoter, which is not as strong as the CMV promoter. Therefore, proteins expressed from these vectors may not be sufficient to perform Western blots or coimmunoprecipitation analyses. Clontech provides another set of expression vectors for the analysis, that is, pCMV-myc and pCM-HA, driven by CMV promoter. Other CMV-based mammalian transcription vectors, such as pcDNA 3.1 can be considered for co-IP or Western blot analysis. Alternatively, there are mammalian two-hybrid vectors carrying CMV promoters, such as pCMX-Gal4-N and pCMX-VP16-N [17].

6. If necessary, other methods should be considered to further confirm the result from the mammalian two-hybrid results. These methods are, but not limited to, GST-pull down assay, fluorescent resonance energy transfer (FRET) or bioluminescence resonance energy transfer (BRET), and mass spectrometry.

7. When pG5SEAP vector alone is used as a negative control, it tends to give high chemiluminescence readings, because no other vector competes for the transfection reagent. When this happens, a "filler" vector (i.e., pcDNA 3.1) that is not related to the mammalian two-hybrid system is recommended (i.e., $800 \mathrm{ng}$ pCDNA $3.1+200$ ng pG5SEAP).

8 . The p53 protein and simian virus large $\mathrm{T}$ antigen have very high interaction kinetics. Such positive control included in the mammalian two-hybrid system may yield very high chemiluminescence reading, thereby obscuring the levels of the targeted protein-protein interactions that otherwise would be easily detected as positive reaction. It is recommended that this positive control be used merely to check if the transfection and SEAP assay are successful instead of comparing with the readings from the targeted protein-protein interactions.

9. The chloramphenicol acetyl transferase (CAT) assay is recommended by some manufacturers; however, in some cases, it is not as sensitive as the SEAP assay. The difference of sensitivity level can be more than tenfold.

10. Since mammalian two-hybrid system demonstrates levels of interactions, it can be used for interaction motif mapping. The commonly used mapping methods are sequential deletions or expression of gene fragments. When the sequential deletion method is used, it is recommended to do both amino- and carboxy-terminal sequential deletion so that functional domains can be better defined.

Acknowledgments We thank Alina Radziwon, Melissa Ballantine, and Todd Cutts for their contributions to the mammalian two-hybrid analysis. This work was supported by the Research Funding for Public Health Agency of Canada.

\section{References}

1. Fry DC, Vassilev LT (2005) Targeting protein-protein interactions for cancer therapy. J Mol Med 83:955-963

2. Arkin M (2005) Protein-protein interactions and cancer: Small molecules going in for the kill. Curr Opin Chem Biol 9:317-324 
3. Tasara T, Hottiger MO, Hubscher U (2001) Functional genomics in HIV-1 virus replication: Protein-protein interactions as a basis for recruiting the host cell machinery for viral propagation. Biol Chem 382:993-999

4. Figeys D, McBroom LD, Moran MF (2001) Mass spectrometry for the study of protein-protein interactions. Methods 24:230-239

5. Trakselis MA, Alley SC, Ishmael FT (2005) Identification and mapping of protein-protein interactions by a combination of cross-linking, cleavage, and proteomics. Bioconjug Chem $16: 741-750$

6. Causier B, Davies B (2002) Analysing protein-protein interactions with the yeast two-hybrid system. Plant Mol Biol 50:855-870

7. Fields S, Sternglanz R (1994) The two-hybrid system: An assay for protein-protein interactions. Trends Genet 10:286-292

8. Fields S, Song O (1989) A novel genetic system to detect protein-protein interactions. Nature 340:245-246

9. Fields S (2005) High-throughput two-hybrid analysis. The promise and the peril. FEBS J 272:5391-5399

10. Miller J, Stagljar I (2004) Using the yeast two-hybrid system to identify interacting proteins. Methods Mol Biol 261:247-262

11. Wildt S, Gerngross TU (2005) The humanization of N-glycosylation pathways in yeast. Nat Rev Microbiol 3:119-128

12. Lehle L (1992) Protein glycosylation in yeast. Antonie Van Leeuwenhoek 61:133-134

13. Davey MR, Blackhall NW, Power JB (1995) Chloramphenicol acetyl transferase assay. Methods Mol Biol 49:143-148

14. Yang TT, Sinai P, Kitts PA, Kain SR (1997) Quantification of gene expression with a secreted alkaline phosphatase reporter system. Biotechniques 23:1110-1114

15. Gould SJ, Subramani S (1988) Firefly luciferase as a tool in molecular and cell biology. Anal Biochem 175:5-13

16. White J, Brou C, Wu J, Lutz Y, Moncollin V, Chambon P (1992) The acidic transcriptional activator GAL-VP16 acts on preformed template-committed complexes. EMBO J 11:2229-2240

17. Lee, J. W. and Lee, S. K. (2004) Mammalian two-hybrid assay for detecting protein-protein interactions in vivo. Methods Mol Biol 261:327-336 